\title{
Advance Praise for The Future of Luxury Brands: Artification and Sustainability
}

Never has the luxury industry gone through more disruptive changes than today. Through the themes of artification and sustainability, this book captures the forces that are shaping the luxury sectors - from fashion to hospitality - and provides the reader with a map to navigate the landscape of luxury in the next decade.

-Dr. Federica Carlotto

Sotheby's Institute of Art

What will happen to the economy and culture of luxury in an age of climate crisis? This rich and stimulating collection of papers shows us how elite consumerism is meeting, and even thriving amidst the challenges of an economy moving towards sustainability. The authors confront the key intersection between ethics, the arts, and growing economic inequality.

-Richard Wilk

Distinguished Professor and Provost's Professor Emeritus Indiana University

In The Future of Luxury Brands: Artification and Sustainability, Annamma Joy has collected a variety of essays that explore the interactions between luxury goods, artistic sensibilities, and the ecological impacts of our consumption habits. As adumbrated in a variety of contributions from top-notch scholars in marketing and related areas, luxury goods carry aesthetic resonances that shape the concerns and meanings of our material and spiritual environment. These imbrications gain new dimensions in the age of COVID and find vivid illustrations in the worlds of fashion, oenophilia, and tourism. The resulting implications for consumer value in a changing arena of consumption experiences deserve this kind of careful scrutiny as a key to the essence of the human condition.

\section{-Morris B. Holbrook \\ W. T. Dillard Professor Emeritus of Marketing Graduate School of Business Columbia University}

This book illuminates how luxury brands today navigate the interrelationship between aesthetics and ethics. It investigates the cooptation of art and sustainability by fashion and luxury brands in a bid to reinvent their future, highlighting both the bright side and the dark side of this endeavor. Through a collection of chapters dealing with very different contexts, Professor Joy's book opens a window onto the possible future of luxury in a changing world. 
-Bernard Cova

Professor of Sociology of Consumption and Marketing

Kedge Business School

Bordeaux-Marseille-Paris

Luxury needs always to defend its legitimacy and respectability as it represents the most visible facet of social stratification, economic inequality, and the exceptional lifestyle accessible only to some. Yet its demand is growing in the world as no one wants to be left behind. To offset clients' guilt and build social acceptance luxury must be exemplary: It does it by always redefining the notion of the utmost quality (sustainability) and now presenting itself as a cultural sector far from mere materialistic values (artification). This is what A. Joy's book demonstrates with talent.

-Jean-Noel Kapferer Pernod-Ricard Chair on the Management of Prestige Brands

Professor Emeritus, HEC, Paris

As, the editor writes, "The time is past due for a complete re-invention of the fashion industry. . . . Luxury brands, with their global reach, hold on the public's imagination and aspirational dreams, and deep pockets can and should lead the way." Via the marriage of a globally inclusive aesthetics and the emergent principles of sustainable resource circulation detailed in this impassioned collection, the tools to effect this re-invention are in place.

-Eric Arnould, PhD, Dr.h.c. Aalto University School of Business

This collection of innovative studies details how the meanings and value of luxury brands are constituted in a cultural matrix of aestheticizing processes, normative ideals, and societal concerns over sustainability. This book is a must read for anyone interested in the complex social, aesthetic, and moral allure of luxury brands.

-Craig Thompson

Churchill-Bascom Professor of Marketing

University of Wisconsin-Madison 
To my beloved Anniks 
